\begin{tabular}{|c|c|c|}
\hline $\begin{array}{l}\text { PKS } \\
\text { PUBLIC } \\
\text { KNOWLDEE } \\
\text { PROJECT }\end{array}$ & $\begin{array}{c}\text { Revista de GEOGRAFIA } \\
\text { (RECIFE) } \\
\text { nttp://www.revista.uffe.br/revistageografia }\end{array}$ & $\begin{array}{l}\text { OJS } \\
\frac{\text { OPEN }}{\text { OPENAL }} \\
\text { SYSTEMS }\end{array}$ \\
\hline
\end{tabular}

\title{
OUTRAS ESPACIALIDADES NO CINEMA PRODUZIDO EM PERNAMBUCO
}

\author{
Gervásio Hermínio Gomes Júnior ${ }^{1}$ \\ ${ }^{1}$ Mestre em Geografia na Universidade Federal do Rio Grande do Norte.Email: gervasio1989@yahoo.com.br
}

Artigo recebido em 26/08/2017 e aceito em 09/10/2017

\begin{abstract}
RESUMO
As paisagens construídas pelos filmes atuam como uma mediação entre os seus espectadores e o espaço geográfico. Os filmes podem construir espacialidades que se caracterizam por serem abertas - produto de interrelações - múltiplas, e em constante devir. Nesse contexto, o presente artigo pretende analisar as espacialidades construídas pelo cinema produzido em Pernambuco na atualidade, levando em consideração a sua ruptura com um regime de visibilidade regionalista, do qual se supunha espacialidades fechadas, estáticas e essencialistas. Chega-se a essa tese a partir das características específicas do cinema produzido em Pernambuco: a presença de elementos que remetem ao urbano e à modernidade, a influência da prática da brodagem em sua produção e à influência do Manguebeat. Dessa forma, problematiza-se a pertinência do cinema produzido em Pernambuco enquanto construtor de outras espacialidades. Define-se inicialmente o que estamos chamando de espacialidade das imagens cinematográficas. Em seguida, aborda-se elementos presentes nos filmes que confirmam ou refutam a ruptura com espacialidades regionalistas. Por fim, discute-se as implicações políticas dessas outras espacialidades construídas pelo cinema produzido em Pernambuco, apontando para outras formas de se imaginar o espaço, que remetem a uma noção de identidade múltipla, e que provocam e instigam o espectador a refletir sobre o espaço geográfico.
\end{abstract}

Palavras-chaves: Cinema. Espacialidades. Política. Regionalismo. Ruptura.

\section{OTHER SPACIALITIES IN THE FILM PRODUCTION IN PERNAMBUCO}

\begin{abstract}
The landscapes constructed by films act as mediation between their viewers and the geographic space. Films can construct spatialities that are characterized by being open - the result of multiple inter-relations -, and in constant becoming. In this context, the present article intends to analyze the spatialities constructed by the film production in Pernambuco today, taking into account its rupture with a system of regionalist visibility, of which one supposed closed, static and essentialist spatialities. This thesis is based on the specific characteristics of the film production in Pernambuco: the presence of elements that remit to the urban and to modernity, the influence of the practice of "brodagem" in its production and the influence of Manguebeat. In this way, it discusses the relevance of the film production in Pernambuco in constructing of other spatialities. It begins by the definition of what we are calling the spatiality of cinematic images. Then it approaches elements present in films that confirm or refute the rupture with regionalist spatialities. Finally, it discusses the political implications of these other spatialities constructed by the film production in Pernambuco, pointing to other forms of imagining space, which refer to a notion of multiple identity and provoke and instigate the viewer to reflect on the geographic space.
\end{abstract}

Keywords: Cinema. Spatialities. Politics. Regionalism. Rupture. 


\section{INTRODUÇÃO}

O presente trabalho busca discutir a espacialidade das imagens cinematográficas no cinema produzido atualmente em Pernambuco. Parte-se da tese de que essa produção cinematográfica rompe com um regime de visibilidade que supunha uma espacialidade com características regionalistas. Nesse sentido, filmes realizados em Pernambuco caracterizar-seiam antes por produzirem uma espacialidade que, tal como definem Massey e Keynes (2009), é aberta, plural e em constante devir. Já as espacialidades produzidas no âmbito do regionalismo, pelo contrário, caracterizavam-se por serem fechadas, essencialistas e estáticas.

Chega-se a essa tese observando algumas especificidades desse cinema. Em primeiro lugar, a produção de uma espacialidade urbana que recorta as imagens cinematográficas, mesmo aquelas que tematizam o campo ou áreas naturais como o semiárido. Essa espacialidade urbana da imagem cinematográfica salta aos olhos mais facilmente quando se produz uma imagem cinematográfica da cidade do Recife - uma Recife cinemática -, o que é observado, por exemplo, nos filmes dirigidos por Cláudio Assis e Kléber Mendonça Filho.

Em segundo lugar, essa espacialidade urbana está presente também nos signos da modernidade e do urbano que "invadem" determinados espaços, como no caso do cinema e da aspirina nos filmes Baile Perfumado e Cinema, aspirina e urubus, e de personagens estrangeiros, o turco e o alemão nos mesmos filmes. Em terceiro lugar, na associação com o Manguebeat, tanto no que diz respeito à utilização de uma trilha sonora Mangue, sobretudo nos filmes de Cláudio Assis, ou contrastando com as paisagens naturais e regionalistas produzidas novamente em Baile Perfumado, ou ainda na influência no modo de fazer o cinema, a partir da prática colaborativa da brodagem.

O Manguebeat faz eco no cinema produzido em Pernambuco tanto pela associação entre cineastas e músicos, como pela matização no cinema dos discursos e imagens, sobretudo da cidade, produzidas no âmbito desse movimento cultural. A associação entre cineastas e demais pessoas envolvidas nas produções cinematográficas - um colaborando na realização do outro - enseja outro discurso de cidade e, sobretudo, outra espacialidade, caracterizada antes pela pluralidade, pela diversidade cultural e pela construção de laços afetivos na construção de um cinema conceitual e crítico da realidade - um cinema construtor de outras espacialidades.

No entanto, faz-se necessário questionar se este cinema e as espacialidades produzidas por ele remeteriam a uma suposta pós-modernidade, ou seja, a uma maneira pós- 
moderna de ver a cidade e, sobretudo, o fenômeno urbano no âmbito da região Nordeste tal como sugerido em defesa de dissertação de mestrado (GOMES JR, 2016). Não seria cedo afirmar que a espacialidade das imagens elaboradas no âmbito do cinema produzido em Pernambuco rompe totalmente com a espacialidade moderna e regionalista? Não seria arriscado chamar essa produção cinematográfica de pós-moderna?

Nesse contexto, apresentaremos de início o que estamos chamando de espacialidade das imagens cinematográficas ou espacialidades fílmicas. Em seguida, abordaremos a construção de outras espacialidades nas produções já citadas de Cláudio Assis, Kléber Mendonça Filho, Marcelo Gomes, Lírio Ferreira e Paulo Caldas e outros. E, por fim, discutiremos as implicações geográficas, políticas e culturais da produção dessas espacialidades que se distinguem da forma como o espaço é ou era não apenas retratado, mas construído, visualizado e recortado no cinema produzido por um "grupo cultural" específico. O que essas outras espacialidades significam para a forma de se ver o Nordeste?

\section{DEFININDO A ESPACIALIDADE DAS IMAGENS CINEMATOGRÁFICAS}

Ao se falar da espacialidade das imagens cinematográficas, esta refere-se à forma como o espaço é reconstruído ou ressignificado pelo filme. O espaço é ressignificado tanto pelo olhar do cineasta como pelo olhar do espectador que deve ser encarado não apenas como um receptor passivo de imagens. Tanto um como o outro, cineasta e espectador, imprimem ao texto fílmico, os textos que trazem consigo: seus valores, suas visões de mundo, suas ideologias, suas memórias, aspectos de sua formação e de sua classe social, em uma fusão de horizontes hermenêuticos.

Além de produzir um discurso e uma imagem para o lugar - sua paisagem fílmica - a imagem cinematográfica possui uma condição espacial criada pelos movimentos de câmera, pelos planos-sequências, pelos processos de edição e montagem, pela adição de efeitos sonoros e visuais que influenciam as nossas próprias noções de espaço. A paisagem fílmica é constituída nesse sentido de uma paisagem material, concreta, que é a imagem do próprio espaço, seja ele natural ou construído, de uma paisagem sonora e de uma paisagem social. O cinema participa da vida moderna a tal ponto, que ajuda na construção imagética e discursiva dos espaços. No caso das cidades, tanto as conhecemos como as ressignificamos por meio dos filmes, que ajudam a construir a sua imagem. 
A espacialidade, no que diz respeito ao cinema, refere-se também a sua prática socioespacial, seja a produção industrial de blockbusters, ou a produção de um grupo cultural mais restrito, como no caso do cinema que é produzido em Pernambuco. Nesse caso, a paisagem encontra uma dimensão material, concreta, territorial.

No estudo em tela, é possível observar a espacialidade do cinema produzido em Pernambuco a partir dessas três perspectivas. Pode-se mesmo associar esses três pontos de vista, levando-se em consideração que a construção de outra espacialidade por meio da prática socioespacial da brodagem, caracterizada por um modo de produção mais colaborativo pautado em uma rede de capital social, reverbera também em outra espacialidade nas telas, ou seja, em uma nova forma de ver e pensar o espaço, a partir de outros pontos de vista, de outras escalas, e, sobretudo, de outros discursos.

Nesse sentido, o cinema produzido em Pernambuco teria o papel de construir outra forma de ver o Brasil e, sobretudo, o Nordeste, rompendo com o regionalismo e construindo uma espacialidade que traz em muitos aspectos a marca do urbano e suscita, para alguns autores, elementos da pós-modernidade, construindo um espaço que é mais plural e diversificado e, por isso, de difícil compreensão.

A abordagem geográfica dos filmes parte do estudo dos espaços a partir do cinema, ou seja, trata-se de estudar a forma como estes espaços são compostos pelos filmes. Considerase, nesse sentido, a importância do cinema em construir as imagens dos lugares, mediando nossa relação com o espaço, a partir da forma de vê-lo - das paisagens. Os filmes constroem paisagens. Nosso interesse é sempre com o espaço concreto, com o território, e a forma como esse é composto paisagisticamente pelo cinema, tornando-se paisagem fílmica - esse constructo, recorte espacial, modo de ver o lugar e o mundo. Mesmo quando o filme constrói um lugar imaginário ou fictício, nossa preocupação é de como ele compõe o espaço, que é sempre o referencial de significação para o cinema, seja em um filme de fantasia ou um documentário.

Lembrando Besse (2014), ao fazer referência à noção de paisagem de John B. Jackson, em que a paisagem além de uma maneira de imaginar o mundo é uma realidade objetiva, material, produzida pelos homens, ela não é apenas vista por uma cultura, mas é produzida dentro de um conjunto de práticas econômicas, políticas e sociais, e segundo valores que ela simboliza.

E de que forma o espaço é construído nos filmes, de que maneira ele é visualizado? Ele remete à tradições - à heranças passadas de geração a geração de uma forma específica de 
visualizá-lo, a uma visão estreita de cultura que a encara como simples transmissão de saberes, valores, crenças etc.? Ou ele se coloca à construção de um espaço futuro, ainda não concretizado, que está por vir? A um outro caminho, outra possibilidade - a própria possibilidade de modificar a cultura? Este último viés parece ser o que mais se assemelha a forma como o espaço tem sido encarado, ou "escancarando" na atualidade, ou seja, não como um sistema fechado, mas sim como múltiplo, rizomático, para usar o conceito de Deleuze e Guattari $^{1}$ (1995), ou seja, sem as entradas e as saídas pré-definidas de uma estrutura fechada, mas tomado de possibilidades, de "linhas de fuga", assim como o rizoma. O espaço nunca é uno, mas sim múltiplo, nunca é fechado, mas sim aberto, está sempre em constante devir, como coloca Massey (2009).

Assim, é também a espacialidade dos filmes, intertextual, é a interpretação que fazemos do olhar do cineasta, numa fusão de horizontes hermenêuticos (MACIEL, 2009). Ele não é a simples imposição de uma ideologia dominante de cima para baixo. Não somos receptores passivos, temos nossos próprios referentes ideológicos (BERDOULAY, 2012). A paisagem fílmica se apresenta como uma matriz de possibilidades; o espaço se apresenta múltiplo; e o filme por meio da paisagem, tem a função de mediar nossa relação com esse espaço, a imagem está lá, ela pode nos suscitar a reflexão, a crítica, a desesperança de um espaço distópico onde nada faz sentido, ou a esperança de um espaço utópico, uma nova forma de olhar que interferirá na forma como compreendemos e, porque não, como interagimos com nós mesmos e com o próprio espaço.

Modelar a forma como conhecemos os lugares é por si só razão o bastante pela qual a imagem cinematográfica possui uma importância especial para a Geografia. O real é uma construção e o mundo só faz sentido quando representado. O espaço é legitimado por imagens. Mas, não custa lembrar que o interesse da geografia é na forma como os espaços são construídos nos filmes, é no diálogo que as paisagens fílmicas mantêm com o espaço concreto. O interesse da Geografia é com os espaços e a forma como esses são construídos no cinema e não só com os filmes, uma vez que os espaços estão lá, "out there", independente dos filmes.

Mas não se trata apenas de revelar a marca de um discurso dominante na paisagem (BERDOULAY, 2012), o que reduziria a paisagem à ideologia, a uma projeção de valores, sem saber, no entanto, as opções e escolhas dos sujeitos, que possuem, por sua vez, seus próprios referentes ideológicos. Considerar a paisagem como mera marca ou expressão de

${ }^{1}$ Os rizomas diferem das raízes com suas estruturas hierárquicas. 
uma ideologia dominante remeteria a fechá-la, a aprisioná-la como coloca Deleuze e Guattari (1995) a multiplicidade de sua espacialidade a uma estrutura, desconsiderando a complexidade do real, do espaço e do filme, em que o mundo não se divide em mero dualismo de dominantes e dominados, mas sim em um espaço onde cada sujeito possui suas próprias ideias, valores, crenças, atitudes, sensibilidades, preconceitos etc. Assim, supõe-se que o espectador se coloca de maneira ativa diante do filme; que o filme é responsável por mediar sua relação com o espaço a sua volta, através das paisagens fílmicas na criação ou na projeção de outras espacialidades, de outros lugares.

\section{OUTRAS ESPACIALIDADES NO CINEMA PRODUZIDO EM PERNAMBUCO}

Após a retomada do cinema no Brasil durante os anos 1990, Recife/PE destacou-se como um importante espaço da produção cinematográfica brasileira, o qual se distingue dos demais na medida em que possui características que lhe são próprias. Em primeiro lugar, destaca-se desde O Baile Perfumado (1997), de Lírio Ferreira e Paulo Caldas - longametragem que marca a retomada do cinema em Pernambuco - a forma colaborativa de se realizar o cinema nesse estado, designada por brodagem, fenômeno social no qual os sujeitos envolvidos com a produção cinematográfica ajudam-se mutuamente, figurando um na realização cinematográfica do outro.

Em segundo lugar, a brodagem assumiu um papel tão importante nos últimos anos no cinema realizado em Pernambuco que ela extrapolou a esfera da produção material propriamente dita do cinema para atingir o campo do seu discurso, chamando a atenção de alguns autores para um suposto cinema pernambucano que teria como uma de suas principais marcas a sua forma colaborativa de realização (NOGUEIRA, 2009, 2014) ou como modo de fazer que distinguiria o grupo cultural que produz cinema em Pernambuco (SILVA, 2015). A brodagem acabaria revelando um cinema rotulado como pernambucano, o qual possuiria um estilo próprio e um modo de fazer distintivo que se caracteriza pela coletividade e pelos laços afetivos entre os realizadores que fazem parte do grupo de cineastas envolvidos com a retomada do cinema em Pernambuco. Além disso, a frequência de filmes produzidos no estado desde os anos 1990, o incentivo dos governos estaduais e municipais para a continuidade dessa produção e ainda a recepção positiva dos filmes pelo público e pela crítica em festivais de cinema nacionais e internacionais são fatores que levaram a se falar de um 
“cinema pernambucano", ou de um novo ciclo de cinema em Pernambuco, cuja principal marca seria, por sua vez, a brodagem.

Em terceiro e último lugar, destaca-se também uma continuidade temática e estilística na forma como o espaço é representado em que o urbano e a modernidade envolvem os filmes mesmo quando esses constroem ambientes rurais ou contextos históricos passados, como é o caso de Cinema, Aspirinas e Urubus (2005) de Marcelo Gomes e, mais uma vez, de $O$ Baile Perfumado, em que paisagens do semiárido nordestino são "invadidas" pelo moderno que ora se faz presente por meio da trilha sonora Manguebeat ou, como constata Silva (2015), por meio sempre de um elemento "estrangeiro", exógeno ao ambiente, como é possível observar nos dois filmes citados: no alemão que percorria o sertão nordestino divulgando e vendendo aspirinas, no caso de Cinema, Aspirinas e Urubus, ou no cinegrafista turco contratado por Lampião para que este filmasse e propagasse a imagem de seu bando no cinema (o que havia de mais moderno no período), no caso de $O$ Baile Perfumado. O urbano e a modernidade estão presentes também quando os filmes situam-se na própria Recife, evidenciando as desigualdades presentes no espaço urbano e a problemática da vida nas grandes cidades, além de conferir aos filmes um caráter universal e cosmopolita, é o caso de filmes como Amarelo Manga (2003) e Febre do Rato (2012), de Cláudio Assis, Árido Movie (2005), de Lírio Ferreira, Deserto Feliz (2007), de Paulo Caldas, Era Uma Vez Eu, Verônica (2012), de Marcelo Gomes, e O som ao redor (2013) e Aquarius (2016), de Kleber Mendonça Filho.

O que esses filmes têm em comum é sempre uma crítica à sociedade que é feita por meio de um discurso contestatório e apresentada seja por meio de paisagens excluídas, como é evidente nos filmes do cineasta pernambucano Cláudio Assis, seja em paisagens hegemônicas, como no caso de $O$ Som ao Redor que, de qualquer forma, não deixam de fazer a crítica à sociedade, apresentando as vicissitudes, os conflitos e as contradições da classe média que vive em Recife. Acompanhando esse discurso contestatório que se manifesta e se expressa nas paisagens construídas pelos filmes há sempre outra alternativa de sociedade e de cidade, um outro olhar, voltado por sua vez para a pluralidade e para diversidade cultural, para outras espacialidades e sociabilidades, para identidades e espaços múltiplos.

Aqui, acontece também uma suposta ruptura, ou uma descontinuidade - à maneira de Foucault (1999) -, com a imagética regionalista a tanto tempo reproduzida e, por isso mesmo, desgastada, a qual reproduzia um Nordeste rural, em ruínas, um espaço da saudade de um passado mais próspero - aquele das oligarquias provenientes da cultura da cana-de-açúcar - 
forma de ver e dizer a região que, como coloca Albuquerque Júnior (2011), servia como base para a manutenção das elites agrárias no poder. Ao contrário, o que se vê no cinema produzido em Pernambuco na contemporaneidade são filmes cortados pelo urbano por todos os lados - mesmo quando locados fora das grandes cidades - seja nos modos de vida abordados pelas suas personagens, sejam nas tematizações, ou, ao apresentar os problemas inerentes a vida em uma metrópole, e ao denunciar e questionar o modelo urbano. Uma espacialidade urbana recorta e delimita esses objetos fílmicos rompendo com a espacialidade que se delineava no regionalismo. O que vemos expressa nessas paisagens fílmicas é antes uma espacialidade múltipla, em constante devir e nunca fechada tal como sugerem Massey e Keynes (2009), ao contrário do regionalismo, do qual podíamos atribuir uma espacialidade essencialista, una e fechada que tem como principal elemento o tradicionalismo.

O que se nota nesses filmes é antes uma estética e um discurso supostamente modernista do que regionalista e, nesse ponto, é preciso ressaltar a influência do Manguebeat ou de uma "cultura mangue" presente em todos os filmes e lembrar que ela, assim como o modernismo na década de 1920 e o Tropicalismo no final dos anos 1960, tem como principal ideia, fundir "antropofagicamente" a cultura universal a uma cultura local, dando origem a uma cultura nacional, mas de caráter profundamente universal e cosmopolita, valorizando sempre as inter-relações e as diferenças no interior dessa cultura. Vale salientar que essa influência não está presente apenas na estética das imagens como é mais uma vez evidente nos filmes de Cláudio Assis, nem apenas numa "musicalidade mangue”, própria do lugar Recife - presente na paisagem sonora (soundscape) dos filmes, mas também na própria prática sociespacial da brodagem, ao lembrar que a retomada do cinema em Pernambuco se deu justamente ao mesmo tempo em que o Manguebeat "aflorava" e que os diálogos e a convivência entre cineastas e músicos era intensa, um interferindo no modo de fazer e na forma como pensar a cultura, a sociedade e a cidade do outro. A relação entre o Manguebeat e a retomada da produção cinematográfica em Pernambuco nos anos 1990 levou com que alguns autores falassem de uma estética mangue presente nos filmes produzidos em Pernambuco (FONSECA, 2006), sobretudo em filmes como O Baile Perfumado e Amarelo Manga, ou que falassem de um Manguebeat cinematográfico, em que os cenários, as cores, os sons e as sensações do movimento Manguebeat conseguiram ser matizados imageticamente pelo cinema, no caso de Amarelo Manga (FERREIRA, 2005). Nesse sentido, a relação entre o Manguebeat e a retomada do cinema produzido em Pernambuco iria além de simplesmente terem aflorado no mesmo momento, mas sim por compartilharem das mesmas ideias, dos 
mesmos motivos, e do mesmo contexto de revitalização cultural por que passava a cidade de Recife durante os anos 1990 (MACIEL, 2005).

\section{POLÍTICA DA ESPACIALIDADE DO CINEMA PRODUZIDO EM PERNAMBUCO}

Alguns elementos comuns ao cinema que é produzido atualmente em Pernambuco definem uma ruptura na política da espacialidade construída pelo regionalismo e reproduzida por manifestações artísticas e culturais, entre elas o cinema. Um dos primeiros aspectos é a questão de como a identidade é abordada nos filmes. No cinema produzido em Pernambuco, a identidade é tratada não como um fenômeno dado, natural, mas como uma construção histórica e cultural.

O cineasta não mais enxerga o espaço com um olhar estrangeiro, reproduzindo determinados estereótipos regionais, como se estivesse construindo uma representação do outro. A partir de agora, o cineasta, no âmbito do grupo cultural do qual participa, passa a construir a partir do seu próprio ponto de vista, de suas vivências, experiências e memórias, a sua própria visão do espaço. Daí a construção de uma espacialidade mais plural e mais diversa, sem fórmulas, modelos ou conceitos pré-definidos. Ao invés de espaços fechados, em que "conceitos" e ideias modelam a realidade, utilizando determinados tipos de personagens estereotipados, produz-se um espaço aberto com uma riqueza de situações e personagens. Um espaço múltiplo, de onde, ao contrário do primeiro caso (onde o espaço é modelado por preconceitos), é possível conceber uma série de interpretações ou experimentações.

O espaço é construído levando em conta o seu devir e a sua multiplicidade. Ele não se fecha a uma única interpretação assim como no caso do regionalismo. Constrói-se uma identidade múltipla e em constante transformação, não há tipos específicos ou apenas uma única versão ou visão de espaço ou cidade. Daí os personagens nada típicos, como no caso dos filmes de Cláudio Assis (Amarelo Manga, Baixio das Bestas e Febre do Rato), e da paisagem deteriorada que esses filmes constroem, mostrando outra Recife (exceto no caso de Baixio das Bestas). Dando ênfase ao urbano e aos problemas urbanos e apontando para outra forma de ver a cidade, como no caso de Febre do Rato.

Muitos autores apontam para o realismo presente nos filmes de Cláudio Assis, o choque do real, ou a crueza presente nas imagens, e de fato o mundo e o devir se fazem presente em seus filmes de maneira contundente, nos afetando e, sobretudo, instigando uma crítica do real a todo instante. Contudo o caráter ideológico de suas obras ainda guia nosso 
olhar a determinada interpretação, seja ao mostrar as desigualdades sociais no campo (Baixio das Bestas), na cidade (Amarelo Manga) e a opção, a alternativa por outro modo de vida em Febre do Rato. Aspectos do rural e do regionalismo ainda estão presentes, mas de toda maneira dá-se a ruptura.

Outro aspecto dessa ruptura com a espacialidade construída no âmbito do regionalismo é o ponto de vista, a escala ou o recorte urbano no qual o espaço é construído. Não é apenas a cidade que aparece em diferentes pontos de vista ou em suas diferentes versões no caso de Cláudio Assis e Kléber Mendonça Filho, ou ainda, a violência, a pobreza, a solidão nas grandes metrópoles ou a fragmentação das identidades como comentado anteriormente. Trata-se de um olhar urbano. O espaço é visto de um ponto de vista urbano, o que faz com que mesmo quando o campo ou espaços naturais sejam construídos, eles o são de maneira moderna e inovadora.

O campo, entendido enquanto formação socioespacial, não é mais representado do ponto de vista do rural, do regional; isto é, do estereótipo, do caricato, do animalesco. $\mathrm{O}$ campo ora é representado a partir de sua miséria e de sua contiguidade com a cidade e os problemas urbanos, remetendo às relações cidade-campo (Baixio das Bestas), ora é invadido por signos do urbano e da modernidade, como em Baile Perfumado e Cinema, Aspirinas e Urubus.

A espacialidade que se constrói no cinema produzido em Pernambuco, por mais que traga ainda signos do rural, como em Amarelo Manga, é eminentemente urbana, o que não quer dizer que os filmes construam apenas espaços urbanos, citadinos, mas que abordam o campo ou a natureza o olhando não da forma estereotipada do regionalismo, mas a partir de outros ângulos, subvertendo e deslocando a imagem que se tem desses espaços, sobretudo quando agenciando outros textos, tais como o Manguebeat, quando a trilha sonora Mangue contrasta com as paisagens naturais em Baile Perfumado ou quando o cinema e a aspirina, símbolos da modernidade, chegam ao sertão.

O urbano aqui aparece mais como processo do que como forma. Enquanto no regionalismo construía-se um espaço que era eminentemente rural, já que o regionalismo era o discurso das elites rurais em decadência, no cinema produzido atualmente em Pernambuco constrói-se uma espacialidade urbana e múltipla, sobretudo quando se questiona o modelo de cidade e o modo de vida urbano. Quando se procura pensar em outras maneiras de ver e vivenciar a cidade, quando se imagina outras espacialidades como no caso de Febre do Rato de Cláudio Assis e dos filmes de Kléber Mendonça Filho. Quando se provoca o espectador e 
o instiga a pensar a quem pertence a cidade. $\mathrm{O}$ que nos leva ao aspecto da prática social do cinema.

A brodagem é outro aspecto que chama atenção e que se configura como marca do cinema que é produzido em Pernambuco, levando alguns autores a chamarem, como já apontado, de "cinema pernambucano" ou de grupo cultural. A brodagem se caracteriza por um modo de produção mais colaborativo em que um trabalha na produção do outro. Trata-se da construção de uma outra espacialidade, na medida em que o cinema é produzido a partir dos laços afetivos construídos entre os cineastas e demais pessoas envolvidas, e que essas pessoas envolvem-se no mesmo ideal de construção de um cinema conceitual e crítico da realidade e, sobretudo, na construção de uma outra espacialidade que resvala para além das telas, tendo um compromisso político e um projeto comum de mudança cultural e social, da construção de espaços mais justos, por meio do cinema.

\section{REFERÊNCIAS}

ALBUQUERQUE JR., Durval Muniz. A invenção do Nordeste e outras artes. $5^{\text {a }}$ ed. São Paulo: Cortez, 2011.

BERDOULAY, Vincent. Espaço e Cultura. In: CASTRO, Iná Elias; GOMES, Paulo Cesar da Costa; CORRÊA, Roberto Lobato (Orgs.). Olhares geográficos: modos de ver e viver o espaço. Rio de Janeiro: Bertrand Brasil, 2012.

BESSE, Jean-Marc. O gosto do mundo: exercícios de paisagem. Rio de Janeiro: EDUERJ, 2014.

DELEUZE, Gilles; GUATTARI, Felix. Mil platôs: capitalismo e esquizofrenia. Rio de Janeiro: Editora 34, 1995.

FERREIRA, Alexandre Figueirôa. O manguebeat cinematográfico de Amarelo Manga: energia e lama nas telas. In: Congresso Brasileiro de Ciências da Comunicação, 28 ${ }^{\circ}, 2005$, Rio de Janeiro. Anais..., Rio de Janeiro, UERJ, 2005.

FONSECA, Nara Aragão. Da lama ao cinema: interfaces entre o cinema e a cena mangue em Pernambuco. Dissertação (Mestrado em Comunicação) - Programa de Pós-Graduação em Comunicação, Universidade Federal de Pernambuco, 2006.

FOUCAULT, Michel. As palavras e as coisas: uma arqueologia das ciências humanas. 8. ed. São Paulo: Martins Fontes, 1999. 
GOMES JR, Gervásio Hermínio. Recife cinemática: as paisagens fílmicas em Amarelo Manga e Febre do Rato. Dissertação (Mestrado em Geografia) - Programa de Pós-Graduação e Pesquisa em Geografia, Universidade Federal do Rio Grande do Norte, 2016.

MASSEY, Doreen; KEYNES, Milton. Filosofia e política da espacialidade: algumas considerações. GEOgraphia. Niterói, Ano. 6, n. 12, p. 7-23, 2004.

MACIEL, Caio Augusto Amorim. Espaços públicos e geo-simbolismos na "cidade-estuário": rios, pontes e paisagens do Recife. Revista de Geografia (Recife), v. 22, p. 12-20, 2005.

A retórica da paisagem: um instrumento de interpretação geográfica. Espaço e Cultural (UERJ), v. 26, p.32-48, 2009.

NOGUEIRA, Amanda Mansur Custódio. O novo ciclo do cinema em Pernambuco: a questão do estilo. Dissertação (Mestrado em Comunicação) - Programa de Pós-Graduação em Comunicação, Universidade Federal de Pernambuco, 2009.

A brodagem no cinema em Pernambuco. Tese (Doutorado em Comunicação) Programa de Pós-Graduação em Comunicação, Universidade Federal de Pernambuco, 2014.

SILVA, Renato Kleibson da. O som ao redor do baile: retomada e pós-retomado no cinema produzido em Pernambuco. Dissertação (Mestrado em Ciências Sociais) - Programa de PósGraduação em Ciências Sociais, Universidade Federal do Rio Grande do Norte, 2015. 